\title{
Patient Behavior: an extensive review
}

\begin{abstract}
The most frequent causes of death in the United States and globally are chronic diseases, including heart disease, cancer, lung diseases, and diabetes. Behavioral factors, particularly tobacco use, diet and activity patterns, alcohol consumption, sexual behavior, and avoidable injuries are among the most prominent contributors to mortality. Projections of the global burden of disease for the next two decades include increases in noncommunicable diseases, high rates of tobacco-related deaths, and a dramatic rise in deaths from HIV/AIDS. Worldwide, the major causes of death by 2030 are expected to be HIV/AIDS, depressive disorders, and heart disease. At the same time, in many parts of the world, infectious diseases continue to pose grim threats, especially for the very young, the old, and those with compromised immune systems. Malaria, diarrheal diseases, and other infectious diseases, in addition to AIDS, are major health threats to the poorest people around the world. And, like chronic diseases, their trajectory may be influenced by the application of effective health behavior interventions. Substantial suffering, premature mortality, and medical costs can be avoided by positive changes in behavior at multiple levels. Most recently, there has been a renewed focus on public health infrastructure to plan for emergencies, including both human-made and natural disasters. During the past twenty years, there has been a dramatic increase in public, private, and professional interest in preventing disability and death through changes in lifestyle and participation in screening programs. Much of this interest in disease prevention and early detection has been stimulated by the epidemiological transition from infectious to chronic diseases as leading causes of death, the aging of the population, rapidly escalating health care costs, and data linking individual behaviors to increased risk of morbidity and mortality.
\end{abstract}

Keywords: health beliefs and perception, patient counseling, patient comprehension and recall, patient motivation, patient feedback, patient compliance
Volume 6 Issue 3 - 2019

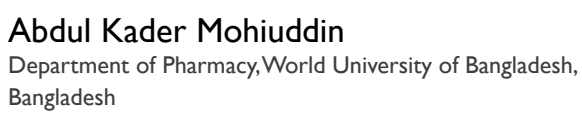

Bangladesh

Correspondence: Mohiuddin AK, Assistant Professor, Department of Pharmacy, World University of Bangladesh, 151/8, Green Road, Dhanmondi, Dhaka-1205, Bangladesh, Tel +8801716477485, Email trymoh@gmail.com

Received: April 24, 2019 | Published: May 21, 2019

\section{Background}

Patient behavior is often described as disruptive behavior as they have an altered mental stage of fear of being sick, anxious about out of the pocket cost, alteration of lifestyle if suffered from a chronic illness. And the outcomes often faced by providers are inappropriate language, make unreasonable demands, and may even resort to physical abuse. The article comprises a few of this unusual behavior and a simple comparison between patients from developed world with those of the under-developed east. Programs to influence health behavior, including health promotion and education programs and interventions, are most likely to benefit participants and communities when the program or intervention is guided by a theory of health behavior. Theories of health behavior identify the targets for change and the methods for accomplishing these changes. Theories also inform the evaluation of change efforts by helping to identify the outcomes to be measured, as well as the timing and methods of study to be used. Such theory-driven health promotion and education efforts stand in contrast to programs based primarily on precedent, tradition, intuition, or general principles. Theory-driven health behavior change interventions and programs require an understanding of the components of health behavior theory, as well as the operational or practical forms of the theory. The science and art of health behavior and health education are eclectic and rapidly evolving; they reflect an amalgamation of approaches, methods, and strategies from social and health sciences, drawing on the theoretical perspectives, research, and practice tools of such diverse disciplines as psychology, sociology, anthropology, communications, nursing, economics, and marketing. Health education is also dependent on epidemiology, statistics, and medicine. There is increasing emphasis on identifying evidence-based interventions and disseminating them widely. This often requires individual health education and health behavior professionals to synthesize large and diverse literatures. Evidence-based groups like the Cochrane Collaboration (http://www.cochrane.org) and the CDC's (Centers for Disease Control and Prevention) Guide to Community Preventive Services (http://www.thecommunityguide.org) offer regular syntheses of behavioral interventions, some of which include theoretical constructs as variables in analyses of effectiveness.

Purpose of the study: Discussion and projection of behavior pattern, health seeking behavior and monitoring status in both developed and under-privileged countries. The pharmacists have a vital role to play which is discussed along with comparison.

Findings: Developed or under developed country, patients have a separate behavior pattern which develops and worsen with disease progression mostly. So many factors are behind but one thing clearly understood that the handling of such situation is a provider's function, a challenge they have to face along with treatment intervention.

Research limitations: Very few articles found in matters regarding along with a very less interest paid by general people to talk about healthcare matters. It was very difficult to bring out facts of irrational patient behavior, giving it a substantial figure to discuss in this article. However, the major limitation is the article could be a comparison of behaviors of developed and under-privileged countries which requires an enormous exposure and financial support. However, the sole focus was to detail mysterious patient behavior and a greater part is covered. 
Practical implication: The soul of this article was to detail about patient behavior, both in Bangladesh and developed countries. Along with students, researchers and professionals of different background and disciplines, eg. Pharmacists, marketers, doctors, nurses, hospital authorities, public representatives, policy makers and regulatory authorities have to acquire much from this article.

Social implication: Patient behavior is the Sole of healing system and a scope for pharmacists and other healthcare providers to work with in both developed or under developed countries. The article should contribute an integrated guideline for patient compliance, demand rational behavior and last but not the least a silvery lining to better pharmacists' dealings with them in near future.

\section{Introduction}

Over the past two decades, research programs have been established to identify and test the most effective methods to achieve health behavior change. More precise quantification of personal health behaviors and improved health outcomes has grown from partnerships between behavioral scientists and biomedical experts. During this period, findings from some major health behavior intervention studies have become available and have provided important insights for the field. Professionals charged with responsibility for health education and health behavior are, by and large, interventionists. They are action-oriented. They use their knowledge to design and implement programs to improve health. This is true, whether they are working to encourage health-enhancing changes in individual or community behavior or conditions. It is equally true of most health education and health behavior research. Often, in the process of attempting to change behavior, environments, or policies, researchers must do precisely what practitioners do-develop and deliver interventions. At some level, both practitioners and researchers are accountable for results, whether these are measured in terms of participants' satisfaction with programs, or changes in their awareness, knowledge, attitudes, beliefs, or health behaviors, or in their improved decision making; institutional norms; community integration; or more distal results, including morbidity, mortality, and quality of life. Health educators may assess these results anecdotally, complete in-depth qualitative assessments, or conduct rigorous empirical evaluations. The unusual patient behavior toward providers and towards themselves including medication taking is inevitable. An interesting fact is mostly patients avoid going to visit a doctor or pharmacists and when appeared for treatment their behaviors change dramatically which is still unexplained. A National Health Service survey reveals $30 \%$ patients never seek any care due to emotional distress of being ill and again nearly $60 \%$ fail to comply treatment guidelines as directed. Social phobia persists in women who need to go for an intervention for any gynecological disorder. Conversely, children have phobia with the doctors and hospital settings due to some unknown reason. When came late at an advanced disease state, the patient is already in a highly disturbed mental condition and a few situations raise, providers need to face another challenge to tolerate and mitigate them. Practitioners of health education at once benefit from and are challenged by the multitude of theoretical frameworks and models from the social sciences available for their use, because the best choices and direct translations may not be immediately evident. The inherent danger in a book like this is that one can begin to think that the links between theory, research, and health promotion practice are easily forged. They are not. For the unprepared, the choices can be overwhelming, but for those who understand the commonalities and differences among theories of health behavior and health education, the growing knowledge base can provide a firm foundation on which to build.

\section{Materials and methods}

\section{Research design and search strategy}

The research is conducted through secondary data search from several sources from books, technical newsletters, newspapers, journals, and many other sources. The present study was started from the beginning of 2018. PubMed, ALTAVISTA, Embase, Scopus, Web of Science, and the Cochrane Central Register of was thoroughly searched. The keywords were used to search for different publishers' journals like Elsevier, Springer, Willey Online Library, Wolters Kluwer were extensively followed.

\section{Inclusion and exclusion criteria}

Studies regarding psychological and social behaviors were given priorities. Several factors that influence medication taking behavior was collectively analyzed and added to the article. Issues regarding economic and cultural barriers were found to be different from subcontinents, countries and even states. A few interesting features of patient motivation and satisfaction through pharmacist's intervention were added afterwards to maintain a logical sequence. Drug factors, environmental factors and provider-patient interaction followed by pharmacist's role in handling patients and to change or correction of behavior were added to reveal their effect on patient compliance which is the ultimate goal of therapeutic guidelines. Many studies found regarding patient compliance of different health conditions in different countries found to be not within the scope of this article.

\section{Types of medication taking behavior}

a. Compliance: Understanding how medication should be used and its benefit, with sufficient positive motivation, intentions and act accordingly. Concordance is not synonymous with either compliance or adherence.

b. Adherence: The extent to which a person takes medication as prescribed. Adherence is broadly viewed as related to instructions concerning medicine intake, use of medical device, diet, exercise, life style changes, rest and return for scheduled appointments. Compliance and adherence relate to the medicine-taking behavior of the patient. Compliance and adherence can be estimated using prescription claims records, pharmacy dispensing data, validated survey instruments or electric pill counters, as well as direct measures such as serum drug levels.

c. Concordance: A process by which a patient and clinician make decisions together about treatment. Concordance does not refer to a patient's medicine-taking behavior, but rather the nature of the interaction between clinician and patient. It is based on the notion that consultations between clinicians and patients are a negotiation between equals.

d. Persistence: A person's ability to continue medical advice for the intended course, which may range from few days to lifelong. Rates of refilling for prescriptions have been used as a method of measuring adherence and is also another means of testing "persistence". ${ }^{1-3}$ 


\section{Types of patient behavior}

The strands of health behavior are positive or negative health life styles and risk avoidance whereas the sub - concepts of illness behavior is health - seeking behavior, help-seeking behavior, healthcare seeking or treatment seeking behavior, the sick role behavior, and life experiences of living with acute or chronic conditions:

a. Health behavior that is preventive in nature generally is referred to as preventive health behavior. Expanding on the original definition, preventive health behavior is defined as actions taken to prevent illness and maintain physical, emotional, intellectual, spiritual, and social well-being.4 In 2007, the Brookings Institution estimated that only $4 \%$ of the $\$ 1.7$ trillion spent on national health expenditures was for prevention. Older adults, in particular, use less preventive health care services than younger and middle-aged adults: they receive fewer cancer screenings, flu shots, mammograms, and pap smears.5 Examples of preventive health behaviors include

i. Participation in health screening programs

ii. Following healthy diet recommendations

iii. Participation in relaxation and cardiovascular exercises

iv. Creating and maintaining close personal relationships (Exhibit 1)

Exhibit I Types of health behavior ${ }^{5-11}$

To keep oneself away from health hazards and prevent from possible ailment. This includes actions like immunization, exercise, intake of Preventive healthy foods and avoid smoking. Three factors converge to underscore the heightened importance of preventive health care services Health among United States adults. First, there is the rapidly aging population. Second, there is the rising cost of medical care: chronic illnesses Behavior and end-of-life issues that older adults face is expensive. Third, despite spending more on health care than any country in the world, United States adults generally have poorer health and lower life expectancies than those in other developed countries.

This kind of health behavior is manifested when individuals engage in active medical screening to detect or identify the real or potentia Health risk of getting caught by any disease. Usually the detection is carried out before perceiving symptoms of any disease or in other words Behavior at the asymptomatic stage. Many hospitals or voluntary health organizations develop programs of detection of possible risk factors by engaging certain target populations into their mass screening programs.

Health To undertake certain healthy activities and adopt healthy life styles to maintain and promote existing health conditions. The health Promotion promotion can also be achieved through preventive health behavior. According to the WHO, there will be I.2 billion elderly people Behavior around the globe by 2025 and 2 billion by 2050. Performing health promotion behaviors is one of the best ways for people to control their health.

Health protective behaviors are receiving increasing attention for maintaining health and preventing disease.At least $60 \%$ of the burden of diseases around the world is due to unhealthy lifestyles, according to WHO reports. The harm of unhealthy lifestyle activities such

Health Protective as smoking, excess alcohol and fat consumption, lack of exercise, and chronic exposure to environment pollutants has been paid close attention, and has been documented in many studies. Health protective behavior encompasses multiple dimensions, which may include the four aspects of environment, behavior and lifestyle, genetic factors, and health care; or may be expressed by eight key factors, namely, of safety, social security, education, food security, income, ecological environment, sustainable resources, and social justice. HPBS has sufficient validity and reliability to measure health protective behaviors in adults.

b. Illness behavior is any activity undertaken by individuals who perceive themselves to be ill that defines the state of their health and aids in discovering a suitable remedy. ${ }^{12}$

i. The term was introduced by Mechanic and Volkart to describe the individuals' different ways to respond to their own health status. Pilowsky's concept of abnormal illness behavior encompasses several clinical conditions characterized by a maladaptive mode of experiencing, perceiving, evaluating and responding to one's own health status. ${ }^{13}$

ii. Illness behavior is the way persons respond to bodily indications that they experience as abnormal; thus, it involves the manner in which persons monitor their bodies, define and interpret their symptoms, and seek health care.

iii. Individuals attempt to ascribe cause and meaning to their illness symptoms and may self-diagnose and treat.

iv. Alternatively, individuals may visit a doctor or another prescriber and a pharmacist in order to obtain a prescription drug. Illness behavior is not all about the immune response v. Emotional component of illness behavior is, at least partly, shaped by top-down expectations. Helping patients having a realistic expectation of symptoms during treatment of an illness may thus reduce aggravated emotional responses, and ultimately improve patients' quality of life and treatment compliance. ${ }^{14}$

c. Treatment behavior is actions taken to restore health or halt disease progression traditionally have been referred to as sick-role behaviors and now are referred to as treatment behaviors. ${ }^{15-17}$

The concept of sick role was proposed by an American Sociologist Talcott Parsons in his famous book 'the social system' which published in 1951.

i. Kasl \& $\mathrm{Cobb}^{17}$ had mentioned Parsons' sick role as a behavior and as a separate concept different from that of illness behavior particularly in terms of ill person's consideration of himself to be ill in contrast to illness behavior where a person feels himself to be ill, but the purpose of both behaviors (illness as well as sick role behaviors) is same: to recover from sickness/ illness. ${ }^{16,17}$ 
ii. In medical sociology, the familial or culturally accepted behavior pattern or role that one is permitted to exhibit during illness or disability, including sanctioned absence from school or work and a submissive, dependent relationship to family, health care personnel, and significant others. This sick role can be confirmed by a doctor or a member his or her family, community or social group at any level ${ }^{5}$ (Figure 1).

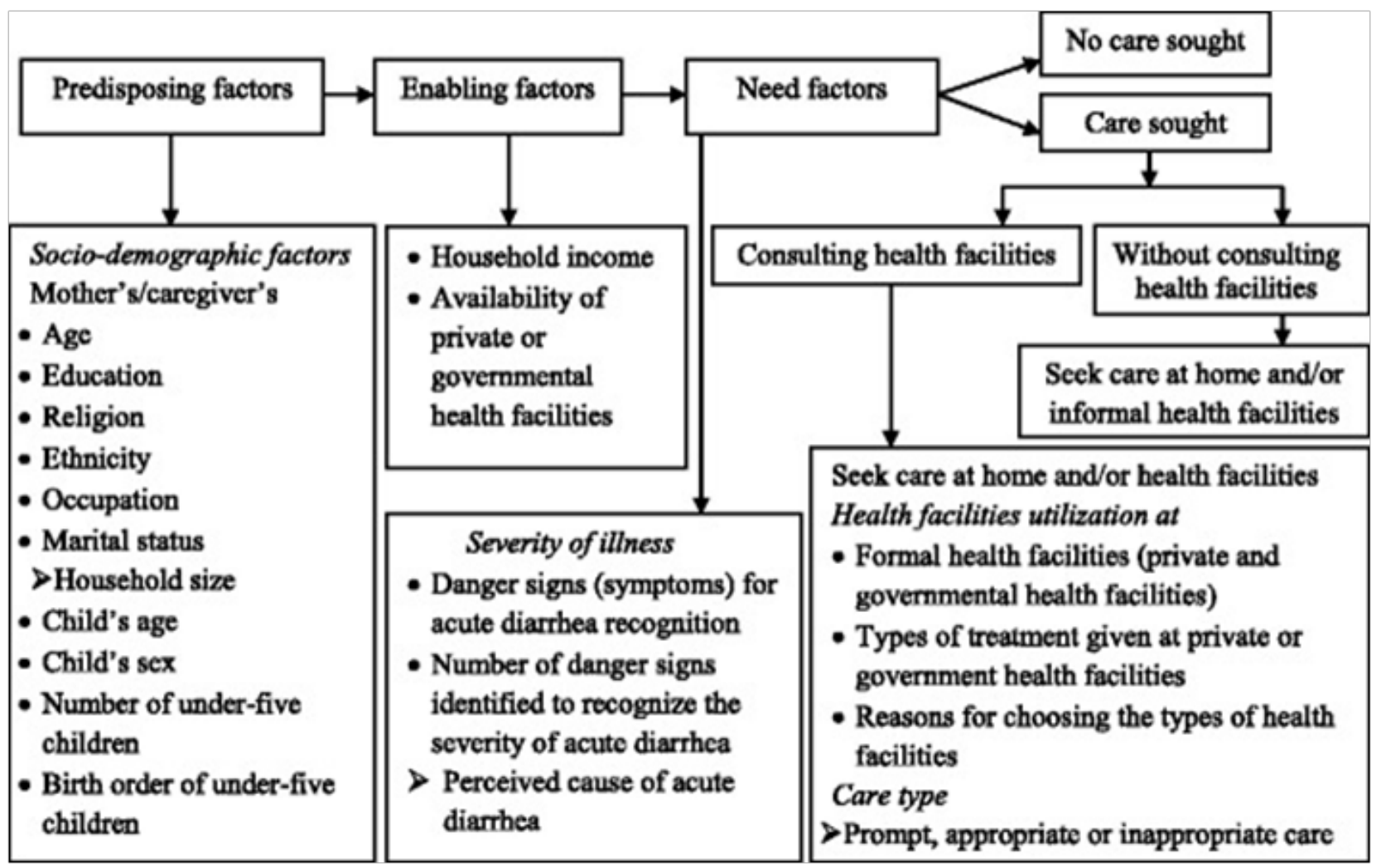

Figure I Conceptual framework for health-seeking behavior modified from Andersen's behavioral model, ${ }^{6}$ which is widely accepted and used to study the predictors of health-seeking behavior and health facility utilization for various diseases, including childhood diarrhea in slums of Addis Ababa, Ethiopia.

Model of Health Services Utilization suggested that three main factors affect an individual's use of health services:

i. Predisposing factors: are those factors that vary an individual's inclination to use services. These predisposing factors include demographic variables such as age and gender; social structure variables such as education, occupation, and ethnicity; and health beliefs about medical care, physicians, disease, and medication use.

ii. Enabling factors: those factors influencing the individual's ability to use services; thus, they reflect the fact that an individual's ability to use services depends on individual family and community resources.

iii. Need factors: those factors related to the individual's belief in the seriousness of illness symptoms and the necessity of intervention. Need factors are separated into two categories, perceived need and evaluated need. ${ }^{18}$

\section{Factors that influence patient behavior}

\section{Patient factors}

a. Age: Older people tend to use health services more than younger people, they account for $34 \%$ of total pharmaceutical expenditures. Nearly $40 \%$ of the elderly have three or more chronic conditions, while about $1 / 3^{\text {rd }}$ of the nonelderly have at least one chronic condition. Younger patients were more likely than older patients to know how their prescribed drugs worked, when it started working, common side effects, how to manage side effects, and how long their physician wanted them to take the medication. ${ }^{19}$

b. Sex: Women tend to use health services more than men. The self-reported use OTC medications in the rural older population also shows that women take more OTC medications than me. ${ }^{20}$ Sex also makes a difference in psychotropic medication use. Marked gender differences have been reported; women are affected twice as often as men. ${ }^{21}$ In addition, women are twice as likely as men to report a positive family history of mood disorder, which is associated with a younger age of onset of depression. ${ }^{22}$ Men receive more consultation from pharmacists. If considering the children, girls are encouraged to express their pain, whereas boys are encouraged to deny their pain and avoid feminine or sissy-like behaviors. ${ }^{23}$ Men disproportionately engage in behaviors that increase the risk of disease or injury, such as smoking and heavy alcohol use, whereas women disproportionately engage in preventive health practices such as use of vitamin supplements, seat belts, and regular screening exams. Verbrugge argued that women are more likely to adopt the sick role and subsequently care for illness or injury in the early stages rather than waiting for symptoms to escalate into more complex health problems. ${ }^{24}$ Women tend to engage in preventive actions like blood pressure and cholesterol checks 
or routine checkups. ${ }^{25}$ Women use a wider variety of self-care activities than men, they are more likely to experiment with new self-care activities and they place greater emphasis on selfcare activities relative to professional health care. ${ }^{26}$

c. Socio-economic level: Higher levels of both income and education are associated with lower rates of mortality. ${ }^{27}$ Five themes emerged for patients who presented late for treatment: lack of knowledge, fear of hospitals, denial, living alone, and preexisting health concerns, found among stroke patients. ${ }^{28}$

d. Ethnic background: Jewish and Italian patients tended to have a more emotional response to pain; they felt freer to discuss their pain, complain about it, groan and cry, and ask for relief. In contrast, patients from other backgrounds tried to deny their pain and appear more stoic. The primary chronic health problem among Mexican Americans in the US is noninsulin-dependent diabetes mellitus. ${ }^{29}$

e. Communication barriers, financial problems, and cultural barriers:

i. Latino patients are often very polite to doctors, so polite that rather than discuss their diabetes care, the patients nod their heads and agree with the doctor. Latino patients with limited English skills may be less likely to take prescribed diabetes medications than other diabetics in the U.S. The "nod of the head" in response to a physician's instructions or comments may therefore represent a socially required gesture of respect, rather than understanding or agreement. ${ }^{30}$

ii. Patients often do not believe that the medication supplies are free and therefore do not take the necessary diabetic supplies as often as needed.

iii. Other patients believe that receiving government assistance in medical supplies will decrease chances of US citizenship. $^{31}$

iv. For the families that do pay for medical supplies, a different problem arises. Expenses for a woman's needs often are considered secondary to the good of her family, and therefore expenditures for diabetes medications and supplies are considered less important than other family necessities. ${ }^{32,33}$

v. Finally, traditional folk remedies, such as aloe, cactus, and garlic, compete with the use of prescribed diet and medications, because patients (and possibly providers) are not aware that treatments can be combined. ${ }^{34}$

f. Emotional factors: Particular concern when the patient has been diagnosed with a terminal illness, an illness with a social stigma, or an illness that requires change in daily behavior. Factors of concern to patients include:

i. Uncertainty of what to expect with this new illness or symptom

ii. Dependency on providers to give the best treatment and on family to help with daily life

iii. Fear of change and death; pain and discomfort

iv. Lack of privacy in physical examinations

v. Loss of identity as a healthy person

vi. Isolation from usual support systems such as coworkers, teammates, and friends; conveying social support also is important, because people are more likely to trust or respond positively to another person if they have an emotionally satisfying relationship with that person. ${ }^{35,36}$

\section{Drug factors}

Drug regimens can be complex. The complexity of a drug regimen often is measured in the:

i. Total number of medications taken daily,

ii. Number of daily doses,

iii. Duration of treatment,

iv. The extent to which the regimen is tailored to daily routines,

v. The side-effect profile. ${ }^{37}$

Medications may require special behaviors, for example:

i. Having to take a dose $1 \mathrm{hr}$. Before or $2 \mathrm{hr}$. after a meal

ii. Avoiding foods that are common in the diet

iii. Taking doses three or more times in a day,

iv. Refrigerator storage, or skill in administration.

v. In addition, just learning the name of the drug prescribed, purpose of the drug, proper dose, when to begin taking it, frequency of dosing, and when to stop treatment is complex.

vi. The complexity of a therapeutic regimen may prevent patients from adhering completely. Complex regimens may produce information overload. ${ }^{38}$

vii. Alternatively, medications requiring behaviors that are difficult to fit into regular daily activities are less likely to be taken as prescribed by a patient. ${ }^{39}$

\section{Environmental factors}

Patients given more autonomy and opportunities for selfdetermination tend to show greater health and morale improvements. The structural layout of many community pharmacies does not include an area for private consultation and dialog between the patient and the pharmacist. In addition to this lack of privacy, pharmacists often experience other environmental barriers to meaningful interaction with their patients, including

i. Insufficient supportive personnel,

ii. A heavy workload and backlog,

iii. People waiting to present prescriptions or receive pharmacist assistance,

iv. Incoming phone calls and requests for information or help from coworkers,

v. Interns, and other staff, and

vi. Inadequate computer technology, software, and

vii. Preparation for new consultation roles. ${ }^{40}$

\section{Provider patient interaction}

Patients can play an important role in improving patient safety by becoming actively involved in their health care. Patients can act as 'safety buffers' during their care but the responsibility for their safety 
must remain with the health care professionals. ${ }^{41}$ Clinical practice often fails to optimize patient participation in decisions about serious illness. Patients prefer that the physician have most of the control over decisions. ${ }^{42,43}$ Patients use three main sources of information when making decisions about their illness and treatment:

i. Their personal experience with the illness and various treatments;

ii. Information obtained from family, friends, and the larger culture;

iii. And their interaction with health professionals.

The patient-clinician relationship has both emotional and informational components - termed emotional care and cognitive care. ${ }^{44}$ Emotional care includes mutual trust, empathy, respect, genuineness, acceptance and warmth. ${ }^{45}$ Cognitive care includes information gathering, sharing medical information, patient education, and expectation management. Providers who adopt an autocratic approach assume a dominant or controlling role, speaking with an authoritarian tone and giving directions without seeking patient input. In contrast, providers who adopt a participatory approach collaborate with the patient to develop a mutually acceptable treatment plan, providing decisional support or guidance without ignoring patient views and demanding compliance with a certain therapeutic plan. ${ }^{46}$

a. Provider instruction on patient comprehension and recall: Physicians and pharmacists continue to be the main sources of drug information and advice given to patients. Patients often receive information about the drug name and recommended dose and dosage frequency, but the majority of patients still receive no specific oral counseling about the purpose of therapy, how long to take their medication, side effects, other precautions, and when the medication will begin to work ${ }^{47}$ In fact, the quality of medication instruction by a provider is a better predictor of patient comprehension and recall than the patient's age and education. Limited literacy has repeatedly been linked to problems comprehending health information, although the majority of studies to date have focused on reading various print health materials. Many older adults may have difficulty remembering verbal instructions conveyed during clinical encounters. Greater provider awareness of the impact of low health literacy on the recall of spoken instructions may guide providers to communicate more effectively and employ strategies to confirm patient understanding. ${ }^{48}$ Research also has shown that there are substantial gains in patient comprehension and recall when providers use

i. Written reinforcement and visual aids, including printed leaflets or information sheets

ii. Expanded prescription labels and stickers

iii. Calibrated liquid measuring devices

iv. And special containers or calendars that indicate exactly when each dose is to be taken. ${ }^{49-57}$ (Exhibit 2)

Exhibit 2 Patient Low Health Literacy (LHL) and Healthcare ${ }^{49-57}$

It is estimated that close to half of the U.S. population has limited health literacy.

According to the Center for Health Care Strategies (CHCS), LHL and insufficient patient education can cost up to $\$ 236$ billion every year.

LHL is associated with multiple adverse outcomes including rates of hospitalization and mortality.

Patients with LHL are more likely to have poor health status, higher rates of hospitalization, and a nearly twofold higher mortality rate.

They are also more likely to experience disparities in health and health care access, have lower rates of screening and preventive services, and obtain their care in the emergency department.

$\S \quad$ Furthermore, patients with LHL are more likely to have poorer knowledge about their disease processes, medication regimens, and methods for managing their disease. LHL also has a negative effect on doctor-patient communication.

The difficulty and length of informational materials can interfere with the patient's ability to comprehend and recall advice.

In general, patients have fewer difficulties if providers simplify instructions by avoiding medical jargon and using shorter words and sentences.

In fact, the patients who received the difficult leaflet made nearly the same number of medication errors as those who received no information.

Amelioration of health literacy of the caregivers will have a direct effect on patient health and prevention of complications.

Knowledge of potential barriers to understanding and completion may improve utilization of and accuracy of patient responses to PFDI-20 and PFIQ-7 (US grade level questionnaire) in women with LHL.

LHL patients did not appear to derive a greater advantage from multimedia, computer-based approach to improve knowledge, attitudes, self-efficacy, and receptivity to cancer clinical trials.

LHL is associated with challenges for those living with HIV including medication non-adherence and poorer health outcomes.AMSTAR checklist by Reynolds et.al., 2019 reveals all of the studies addressed the key significance of health literacy within the scope of living with HIV disease.

b. Provider support on patient motivation and evaluation of care

Being ill and undergoing treatment can involve

i. A variety of stresses, practical problems, and

ii. Other concerns that adversely affect patients' evaluations of treatment and their motivation to perform difficult tasks such as changing an unhealthy life-style, taking multiple medications, tolerating adverse events, and maintaining a positive self-image and outlook

iii. Patients also develop more positive attitudes and achieve better treatment outcomes when their caregivers make a systematic effort to reinforce the value of therapy. This reinforcement can take multiple forms, such as 
iv. Giving feedback to patients about their conditions during follow-up medical and pharmacy visits,

v. Encouraging patients to monitor their own conditions with special devices, or making home visits to increase family support and reinforcement. For example, experimental studies in hypertension management have documented substantial gains in patient adherence and clinical outcomes if patients receive regular blood pressure monitoring and feedback about their condition from a pharmacist or nurse. ${ }^{58,59}$

\section{c. Provider monitoring on patient feedback and satisfaction}

Surveys suggest that patients experience a wide variety of subjective and objective problems and concerns that contribute to nonadherence, dissatisfaction with care, and treatment dropout. These barriers to treatment adherence include

i. Doubts about the physician's diagnosis or need for treatment,

ii. Misunderstandings about the regimen,

iii. Difficulties remembering each dose,

iv. Doubts about the effectiveness of the prescribed drug for their condition,

v. Concerns about side effects and other bothersome features of a drug,

vi. And fears about the long-term effects of treatment or social stigma associated with certain conditions or treatments. ${ }^{60}$

At the same time, physicians and pharmacists do not always ask patients about their medication concerns, beliefs, understandings, and behaviors. While these patient concerns can have detrimental effects on the patient's behavior, many patients are reluctant to complain or ask their providers about their medications. Providers who ask carefully designed, open-ended questions about patient concerns and adherence will be more likely to receive accurate patient feedback than those who wait for their patients to volunteer this information. community pharmacists should equip themselves with appropriate knowledge and competencies in order to tender efficient and outstanding pharmaceutical health care. ${ }^{61,62}$

\section{Behavior: an east west analogy}

As reported by the WHO, patient adherence to long-term therapies is alarmingly low in both developed and developing countries. ${ }^{63}$ Nearly $50 \%$ of antibiotics are purchased and consumed without any medical supervision in most parts of the world ${ }^{64}$ Evil spirits are blamed for epilepsy in most part of the world. Healthcare providers' understanding of their patients' healthcare beliefs, values, and preferences is an important feature of patient-centered care. The use of herbal medicinal products and supplements has increased tremendously over the past three decades with not less than $80 \%$ of people worldwide relying on them for some part of primary healthcare. ${ }^{65}$ Medication nonadherence remains a substantial public health problem. Worldwide, between $25 \%$ to $50 \%$ of patients do not take their medications as recommended. In the USA, suboptimal adherence has been associated with 125,000 deaths, $10 \%$ of hospitalizations, and costs 300 billion USD annually. ${ }^{66}$ The economic impact was also in PubMed and Scopus in September 2017, which shows an increase in total healthcare cost $(>80 \%)$, pharmacy costs
(70\%), inpatient and outpatient costs $(50 \%)$, emergency department visit and medication costs $(<30 \%)$, and hospitalization costs $(<20 \%){ }^{67}$ Across South Asia, overall hypertension prevalence is estimated to be $27 \%$. Prospective Urban Rural Epidemiology study has shown more than $50 \%$ are unaware of it and up to $80 \%$ of hypertensive patients have low adherence to medication. ${ }^{68}$ Uncontrolled BP was found more than $50 \%$ in Bangladesh, $70 \%$ in Pakistan and almost $60 \%$ in Sri Lanka. ${ }^{69}$ American Diabetes Association and the European Association for the Study of Diabetes guidelines in 10 developing countries from Africa (Egypt, South Africa), Middle East (Israel, Saudi Arabia, United Arab Emirates, Iran and Lebanon) and South Asia (Bangladesh, India and Pakistan) shows more than $25 \%$ and around $70 \%$ patients did not have any follow-up visit by a diabetologist or a GP, respectively. More than $35 \%$ patients did not receive any diabetes education. ${ }^{70}$. Lifestyle risk behaviors such as smoking, poor diet, lack of exercise and alcohol misuse contribute to a substantial burden of disease and disability worldwide. In the UK, around $70 \%$ of people engage in at least two of these behaviors. ${ }^{71}$ In the US, 78.6 million people, being obese and the estimated annual cost of obesity reaching approximately $\$ 147$ billion. ${ }^{72}$ AUD was reported in nearly $30 \%$ in rural India ${ }^{73}$ and SLT followed by smoking and dual use of tobacco (paan, paan masala, khaini, zarda and gutka) in nearly $50 \% .^{74}$. In 2015 , along with China, India recorded the highest number of obese children globally. ${ }^{75}$

\section{Behavior: an east west comparison}

\section{Health expenditure and utilization in western countries}

i. $25 \%$ of Hispanic patients report fear that insulin causes blindness. Patients need information that may not appear obvious to providers. ${ }^{76}$

ii. In 2015 , nearly $\$ 3$ trillion USD were spent on healthcare in the United States. $5 \%$ of the total population consumes $50 \%$ of all healthcare spending. ${ }^{77}$ Just over half (54\%) of healthcare funding in the United States comes from private sources, in contrast to just under one-third in Canada (30\%) and Australia $(32 \%)$ and under one-fifth in the United Kingdom (18\%). Public sector spending per capita is more consistent across countries (Canada's expenditure is $5 \%$ greater than that of the United Kingdom and 20\% greater than Australia's). During the year 2016, 91.2\% of Americans had health insurance coverage. Overuse has been best documented HICs. ${ }^{78}$

iii. Australia has the highest number of MRI machines among OECD countries (13.4) per million people but has the lowest MRI exams (27.6) per 1000 people. ${ }^{79}$

\section{Misbeliefs, superstitions and poor compliance in south asian countries}

In Pakistan, $10 \%$ ethnic respondents rely on arm bracelet for pressure control and neem (Azadirachta indica) for diabetes measure; nearly $30 \%$ rely neem chicken pox and measles cure; $16 \%$ went to maulvis for treatment of jaundice; for epilepsy management, $20 \%$ of patients were made to smell shoes and $11 \%$ were taken to peers and faqirs (folk healers)..$^{80}$ "Coining", a similar belief in China, Indonesia and many South Asian countries that rubbing coin along with the skin will bring bad blood to surface. Culturally in many parts of India, menstruation is still considered to be dirty and impure. A nearly $90 \%$ of women in India sometimes resort to using ashes, newspapers, dried leaves and husk sand to aid absorption. ${ }^{81}$ The trend towards finding 
healers first and then doctors covers all fields of medicine in India and beyond. It cannot be wrong to show respect for cultural traditions and belief, but if pursued without heed to possible harms that arise from not seeking timely professional help the situation could change. Furthermore, the situation described is not unlike that which is commonly found in China, where the two different types of medicine (traditional and allopathic) generally work in parallel, and have done for many years. In Bangladesh, diarrhea and pneumonia cause death of more than ten lac children every year. Majority parents seek treatment from homeopaths, folk healers, retailers or non-qualified allopath. ${ }^{82}$ A recent study shows that half of the antibiotics are sold without prescription in most of the South Asian countries, people prefer self-medication rather than visiting a doctor. ${ }^{83}$

\section{Pharmacists' role}

\section{Pharmacists role in improving patient behavior}

a. Establish a relationship

b. Improve the patient and caregiver knowledge base

c. Utilizing digital health technology tools.

d. Providing incentives

e. Involve the caregiver ${ }^{84,85}$

\section{Importance of patient counseling}

Patient counseling is necessary to reduce medication errors and improve patient healthcare (Figure 2). This leads to several potential benefits:

a. Improved therapeutic outcomes and decreased adverse effects

b. Improved patient adherence to the treatment plan

c. Decreased medication errors and misuse

d. Enhanced patient self-management by involving the patient in designing the therapeutic plan

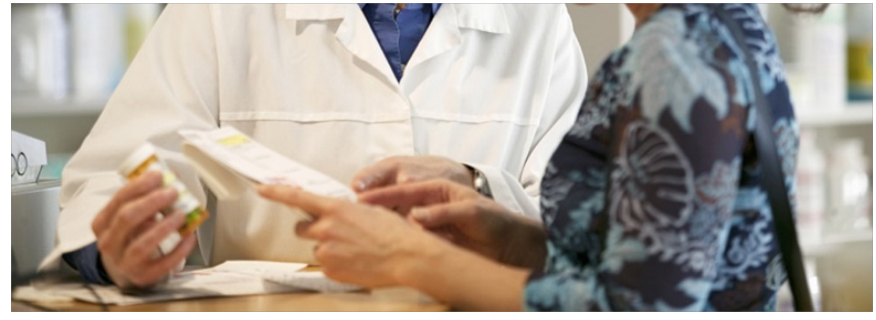

Figure 2 Patient counseling.

Potential for decreased health care costs due to appropriate use of medications and prevention of adverse events. The pharmacist also benefits in this process. Potential benefits to the pharmacist in this process include:

a. Enhanced professional status in the view of patients and other health care providers

b. Establishment of an essential component of patient care that cannot be replaced by technicians or automation

c. Enhanced job satisfaction through improving patient outcomes

d. A value-added service to offer patients

e. Revenue generation through payment for counseling serviceslimited at present but growing

In short, it ensures positive outcomes on the management of disease, including improved drug compliance, better treatment endpoints, and patient satisfaction. ${ }^{2}$ Approaches aimed at promoting patient and family engagement in treatment share the over-arching goal of changing behaviors of patients, families, and healthcare providers and possibly administrators. Patient engagement interventions are complex by nature and involve interacting components intended to produce changes in outcomes and behavior ${ }^{86,87}$ Michie et al. ${ }^{86}$ have generated a taxonomy of 93 BCTs in 16 categories (Table 1) that can be used to specify, interpret, and implement specific techniques used in patient and family engagement approaches.

Table I Overview of patient behavior change techniques ${ }^{103}$

\begin{tabular}{|c|c|}
\hline BCT category & Example and definition \\
\hline Goals and planning & $\begin{array}{l}\text { Problem solving: analyze or prompt the person to analyze factors influencing the behavior and generate or select strategies } \\
\text { that include overcoming barriers and/or increasing facilitators }\end{array}$ \\
\hline $\begin{array}{l}\text { Feedback and } \\
\text { monitoring }\end{array}$ & Feedback on behavior: monitor and provide information on evaluative feedback \\
\hline Social support & Social support (practical): advise on, arrange, or provide practical help for the performance of the behavior \\
\hline Shaping knowledge & Instruction on how to perform the behavior: advise or agree on how to perform the behavior \\
\hline Natural consequences & $\begin{array}{l}\text { Information about health consequences: provide information (written, verbal, visual) about health consequences of } \\
\text { performing the behavior }\end{array}$ \\
\hline $\begin{array}{l}\text { Comparison of } \\
\text { behavior }\end{array}$ & Information about others' approval: provide information about what other people think about the behavior \\
\hline Associations & Prompts/cues: introduce or define environmental or social stimulus with the purpose of prompting or cueing the behavior. \\
\hline $\begin{array}{l}\text { Comparison of } \\
\text { outcomes }\end{array}$ & Pros and cons: advise the person to identify and compare reasons for wanting and not wanting to change the behavior \\
\hline Reward and threat & $\begin{array}{l}\text { Social incentive: inform that a verbal or non-verbal reward will be delivered if and only if there has been effort and/or } \\
\text { progress in performing the behavior }\end{array}$ \\
\hline
\end{tabular}


Table Continued...

\begin{tabular}{ll}
\hline BCT category & Example and definition \\
\hline Regulation & $\begin{array}{l}\text { Conserving mental resources: advise on ways of minimizing demands on mental resources to facilitate behavior change } \\
\text { Restructuring the social environment: change or advise to change the social environment in order to facilitate performance } \\
\text { of the wanted behavior or create barriers to the unwanted behavior }\end{array}$ \\
$\begin{array}{l}\text { Fntecedents } \\
\text { Identity }\end{array}$ & $\begin{array}{l}\text { order to change cognitions or emotions about performing the behavior } \\
\text { Scheduled } \\
\text { consequences }\end{array}$ \\
Self-belief & $\begin{array}{l}\text { Verbal persuasion about capability: tell the person that they can successfully perform the wanted behavior, arguing against } \\
\text { self-doubts and asserting that they can and will succeed }\end{array}$ \\
Covert learning & $\begin{array}{l}\text { Vicarious consequences: prompt observations of the consequences (including rewards and punishments) for others when } \\
\text { they perform the behavior }\end{array}$
\end{tabular}

\section{Benefits of patient compliance}

The improvement of compliance (Figure 3) will result in a situation in which all parties benefit. Most importantly patients benefit from the enhancement of the efficacy and safety of their drug therapy. ${ }^{88}$ Pharmacists benefit because there is an increased recognition and respect for the value of the advice and service that they provide. Pharmaceutical manufacturers benefit from the favorable recognition that accompanies the effective and safe use of their drugs as well as from the increased sales resulting from the larger number of prescriptions being dispensed. Finally, society and the health care system benefit as a result of fewer problems associated with noncompliance. Although an increase in compliance will result in more prescriptions being dispensed and a higher level of expenditures for prescription medications, this increase in costs will be more than offset by a reduction in costs (e.g., physician visits, hospitalizations) attributable to problems due to noncompliance. ${ }^{89,90}$

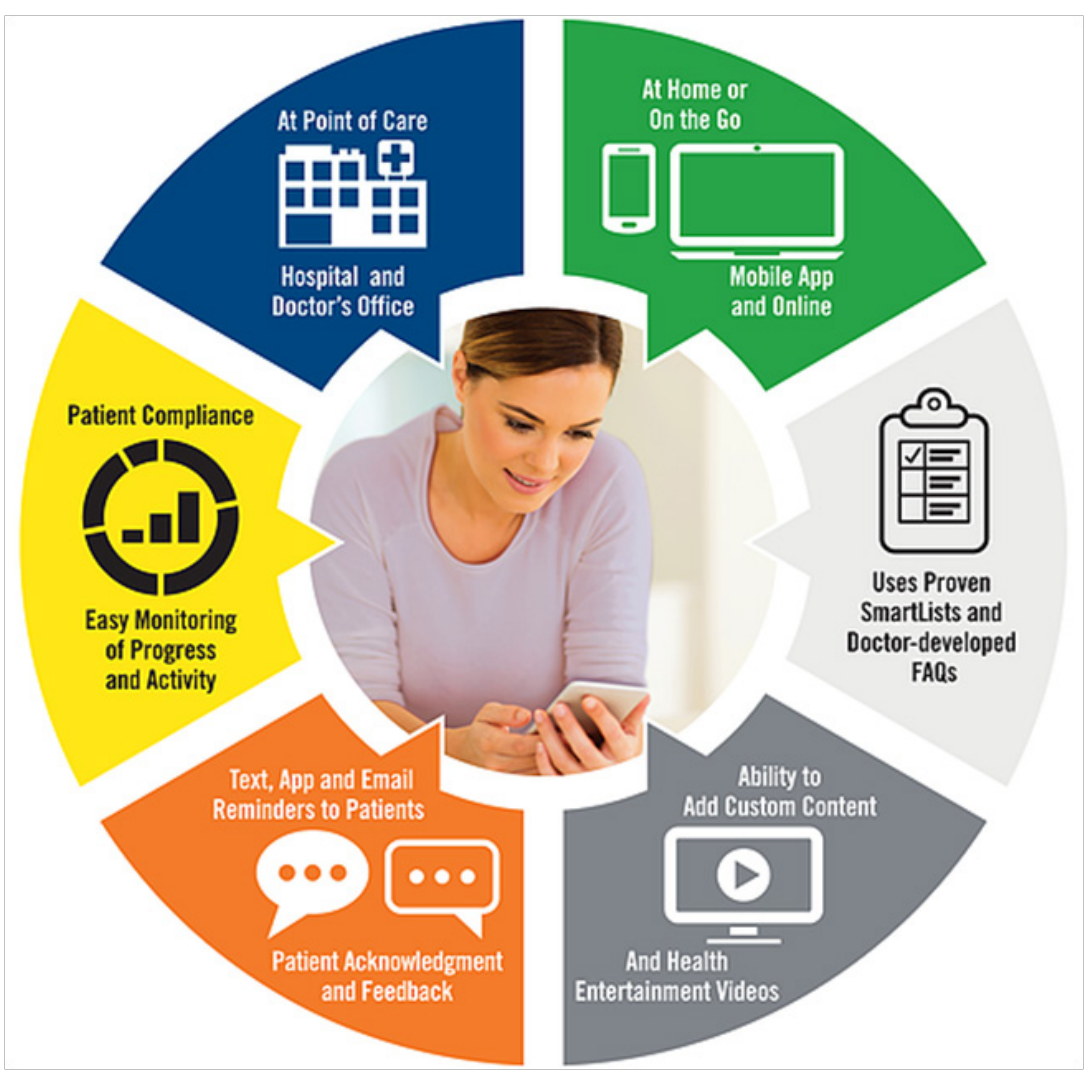

Figure 3 Compliance monitoring. ${ }^{88} \mathrm{An}$ increase in the accessibility of health system data and advancements in electronic information of medication use has permitted new insight into patients' medication behavior. The increased availability of big data in health has enabled the utilization of quality performance measurement across various aspects. Specially, in pharmacy, large data sets of prescription dispensing information, also known as pharmacy claims or prescription refill data, have become more readily available from the ease of electronic information, making it useful for analyzing medication adherence and providing a viable and economical approach for its estimation in real time. Frequently revealed in long-term monitoring are declining trends in adherence, indicating the issue of maintaining adherence over time as crucial as improving adherence at a cross-sectional time point. Instant feedback during the dispensing process can allow the monitoring of patient adherence in real-time, especially by community pharmacists, and therefore, trigger adherence interventions when suboptimal adherence levels are identified. Interventions to improve medication adherence in research projects delivered by community pharmacists have been shown to be more effective. 


\section{Conflict resolution and problem solving}

Because providers and patients are likely to have different viewpoints and agendas, some interpersonal conflict or disagreement is inevitable during their interaction. This conflict is especially likely after patients have gained more experience with their illness and recommended treatments. For example, providers may want patients to comply as fully and rapidly as possible with their ideal treatment plan, whereas patients may prefer a slower or less aggressive approach or even request alternative therapies that providers would consider ineffective, inappropriate, or unnecessary. Providers also may consider certain side effects or drug-taking problems to be clinically insignificant or trivial, while patients consider the same side effects or problems to be intolerable. As a result, providers often are confronted with both explicit and subtle forms of negative feedback from their patients (Figure 4) (eg, complaints about the drug or dosage schedule, admissions of nonadherence, reported difficulties administering or paying for medication, expressions of fear and uncertainty about drug efficacy or safety). In contrast, the participatory/collaborative approach involves acknowledging the legitimacy of patient concerns, assessing patient concerns in a more thorough and respectful manner, tailoring or adjusting drug regimens to fit patient routines and preferences, and negotiating mutually acceptable solutions. Patient adherence is significantly improved if the dosage schedule has been tailored to the patient's daily routine, if the patient is allowed to change the regimen within a preapproved protocol, and if the patient identifies the areas in which he or she would like assistance. ${ }^{91,92}$

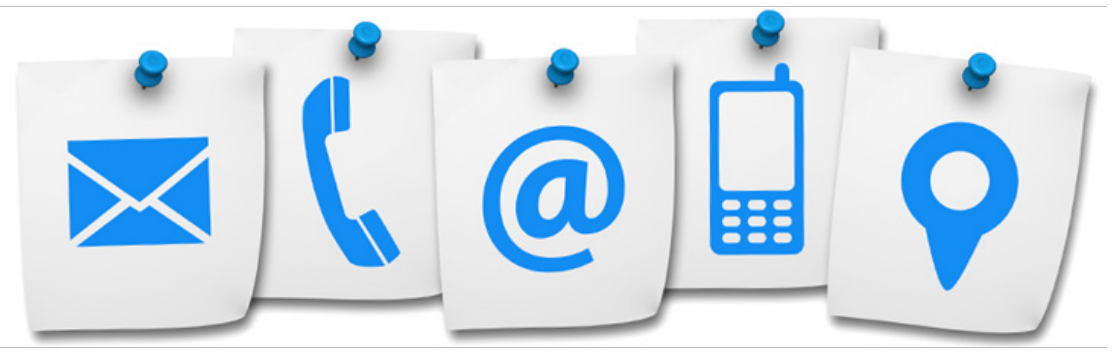

Figure 4 Approaches to receive patient feedback.

\section{Managing disruptive patient behavior}

Patient aggression/disruptive behavior toward healthcare professionals is common and worldwide. These include continual pacing, increasingly agitated appearance, abusive behavior (physical or verbal), obstructing the provision of care, refusing to comply with physicians' orders or caregivers' efforts to provide care, providing erroneous information on purpose, talking loudly or in an intimidating, confrontational, or disrespectful way, making unreasonable demands or using inappropriate language, taking unauthorized drugs or drinking alcohol while on hospital property, leaving the facility without proper authorization, purposely missing treatments or not following through on tests ordered etc. ${ }^{93}$ In 2010, Warren Davis shot his mother's orthopedic surgeon before killing his mother and himself after he learned that back surgery had left his mother paralyzed. In 2014, a strikingly similar situation occurred at Sacred Heart Hospital in Cebu City, Philippines, when a wheelchair-bound patient, who was upset about not being able to walk after spinal surgery, shot and killed his orthopedic surgeon before killing himself. ${ }^{94}$ These behaviors have been linked to adverse events, medical errors, compromises in patient safety, and even patient mortality. ${ }^{95}$ For example, among trainees in seven Canadian residencies, Cook et. al found that $50 \%$ of participants reported psychological abuse by patients, with 10 to $15 \%$ reporting physical assaults by either patients or family members. ${ }^{96}$ In the June 2013 American Nurse Today, 5.6\% of Emergency Department (ED) nurses are victims of violence daily, and over $28 \%$ of ED nurses experience verbal abuse. ${ }^{97}$ One study conducted by researchers at the Portland, Oregon Veterans Administration (VA) Hospital found that $30 \%$ of disruptive patients filed formal complaints about their care to outside third parties. Also, psychiatrists there found that $25 \%$ of patients who were disruptive caused $38 \%$ of the incidents that had been reported. In addition, they noted that disruptive behavior often escalated into more violent behavior. ${ }^{98}$ (Exhibit 3,4 )

Exhibit 3 Steps to be taken to assure that the organization promotes strong communication and a culture of safety going forward 93,95

Consistent enforcement of the Code of Conduct, regardless of status or seniority (i.e. zero tolerance for violations)

Monitoring patients' perceptions of ongoing communications

Assessment of any reports of patients' disruptive behavior or violence, unprofessional staff behaviors, and any actual abuse or allegations of abuse and/ or physical harm that may have resulted from altercations

Development of an interdisciplinary process for addressing adverse events/trends related to unacceptable communication and/or disruptive behavior

Medical staff members need to be included

Representatives from key clinical and nonclinical departments should participate, including human resources and educators

Executive leadership involvement is important

Implementation of additional strategies to promote further improvements in communication styles and to reduce future patient/family/caregiver misunderstandings and frustrations

Recognizing patient anger increases safety for both physicians and patients.

Anger, in itself, has a differential diagnosis that physicians should keep in mind. 
Exhibit 4 BLAST Approaches to Complain Resolution ${ }^{99}$

B Believe

Patients expect to be believed, and belief conveys understanding, support, and empathy. Empathy, the ability to comprehend and communicate understanding of another's emotions and their attached meanings, is highly beneficial in complaint resolution and is fundamental to good doctor-patient relationships.

Active listening requires that the clinician silence his/her inner voice and calmly and patiently attend to the patient without reacting or preparing a rebuttal. Within limits, tolerate anger, rudeness, obscenities, fabrications, exaggerations, personal criticism, histrionics,

L Listen and repetition. Calmly give the patient his/her uninterrupted "magic minute" to describe, explain, criticize, and vent while conveying a sincere interest in hearing the patient. This is facilitated by sitting and facing the patient with an open, relaxed posture; making eye contact, and offering expressions of understanding. Maintaining a quiet mind, emotional control, and attentive posture demonstrates that the clinician is unrushed and empathetic.

The doctor then offers an apology for what the patient is experiencing and for his/her unmet expectations. This apology need not be an expression or acceptance of responsibility. Patients with legitimate complaints deserve an apology, those without legitimate

A Apologize complaints still expect one, and a well-worded apology further defuses the situation. This is why restating patients' complaints in terms of unmet expectations is useful. The apology is an avenue for providing explanations without appearing defensive or accusatory.

The clinician then strives to satisfy the patient. If the patient's suggestions are reasonable, the clinician can simply accede to

S Safety them. Otherwise, calmly explain why they may not be the best choice, 13 propose two or three options (any more is potentially confusing), and let the patient choose. This gives the patient a sense of involvement and control.When the patient has chosen and the details explained, be certain to verify that the patient is satisfied with the solution.

Finally, thank the patient for expressing his/her complaints and concerns and providing a second chance to satisfy him/her.

T Thank

\section{The health collaboration model}

Health Collaboration Model highlights the central role of patient feedback and collaborative problem solving in health care. Each box represents a different set of provider behaviors or background factors affecting the collaboration process; whereas, each circle represents a different set of patient cognitions, beliefs, behaviors, or clinical outcomes affected by collaboration and background factors. ${ }^{100}$ Health
Collaboration Model highlights the central role of patient feedback and collaborative problem solving in health care. The diagram is best understood by beginning at the left side of the diagram and following each arrow in numerical order. Each box represents a different set of provider behaviors or background factors affecting the collaboration process; whereas, each circle represents a different set of patient cognitions, beliefs, behaviors, or clinical outcomes affected by collaboration and background factors ${ }^{101}$ (Figure 5).

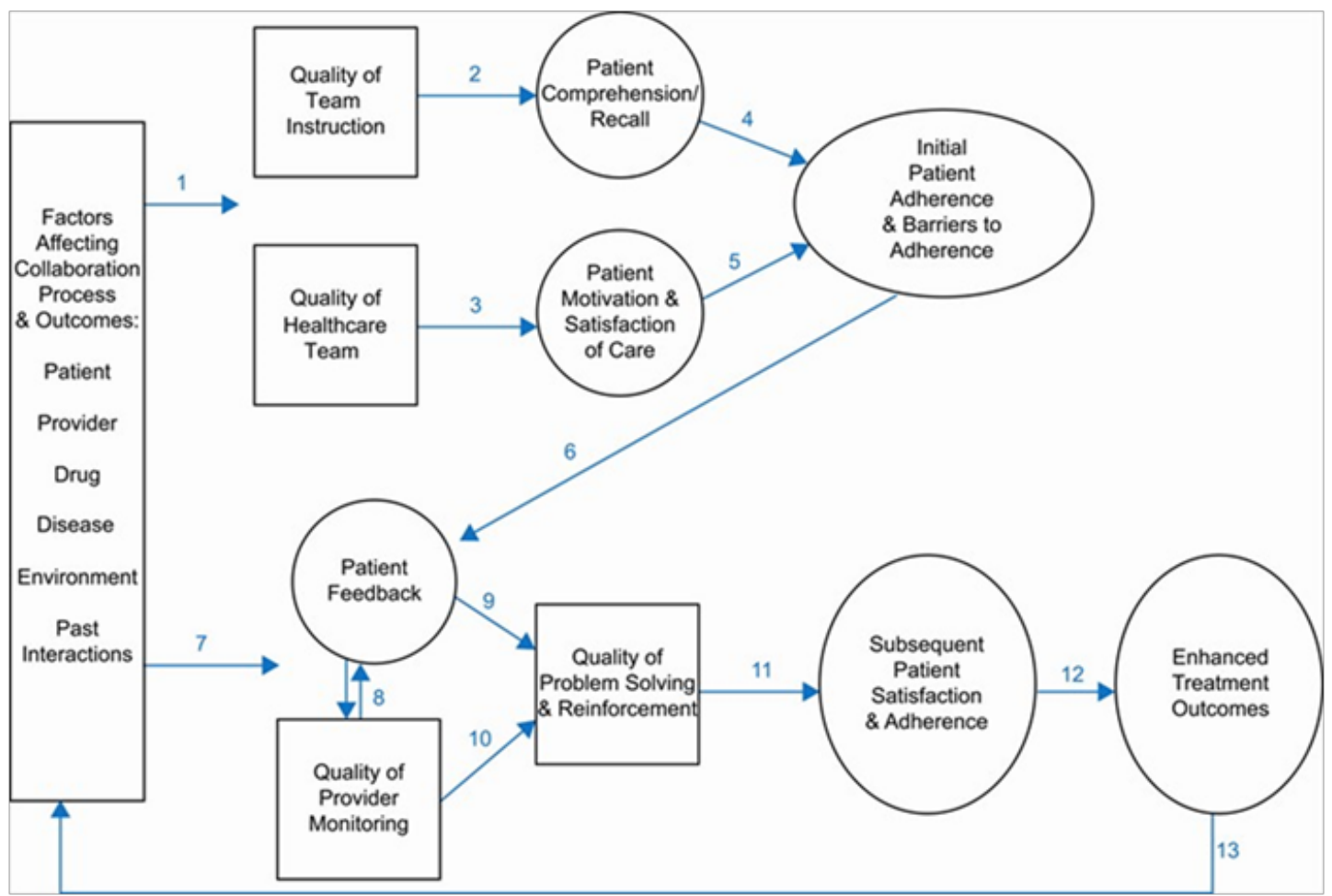

Figure 5 Health collaboration model. ${ }^{102}$ 
The top part of the model (arrows 1-5) emphasizes the various factors that can impact the patient's initial reactions after receiving a new prescription or other new regimen; whereas, the bottom part of the model (arrows 6-13) emphasizes the various factors that can impact the patient's behavior after he/she has experienced the drug and barriers to adherence. First, we see that patient, provider, drug, and environmental factors (arrow 1) can impact both provider and patient behavior during the initial stages of collaboration and treatment, including the quality of provider instruction and support, patient comprehension/ recall and motivation, and initial patient adherence and barriers to adherence. During the initial stages of collaboration, the provider plays a critical role in facilitating and verifying patient comprehension/recall of the regimen (arrow 2). The provider also plays a critical role in facilitating and verifying the patient's initial motivation and satisfaction with the regimen (arrow 3 ). It is not enough to give drug information. Rather, the provider must assess the individual's initial understandings and beliefs and make adjustments as necessary. In some cases, he/she will need to provide additional instruction or reinforcement to make sure the patient will understand and remember the dosage schedule. In other cases, he/ she will need to provide additional informational, social, or technical support to address the individual's initial doubts or concerns about the drug and its short-term or long-term effects. If effective collaboration occurs at this stage, then the patient will have greater comprehension/ recall and greater motivation which, in turn, lead to greater initial adherence and fewer barriers to adherence (arrows 4-5). The bottom part of the model draws attention to the fact that patients actively monitor their reactions to drug therapy and experience a variety of barriers to adherence after initiating therapy. They may find it difficult to remember each dose or simply question whether the drug is still needed or working for them. They also may experience unwanted effects or have concerns about high drug costs, possible dependence, or unknown long-term effects. Since these patient-perceived barriers seriously undermine the patient's willingness and ability to continue therapy as prescribed, patient feedback plays a central role in followup visits with the provider (Figure 1). Soliciting accurate patient feedback is a complex process that depends on: the patient's personal experience with the drug (arrow 6); background characteristics and expectations of the patient and provider, characteristics of the drug and environment, and past patient-provider interactions (arrow 7); and quality of provider monitoring. Providers who regularly ask carefully designed, open-ended questions in a supportive, non-accusatory manner can be very successful in soliciting negative patient feedback even among patients who initially appear reluctant or hesitant to share their personal doubts, difficulties, and concerns. The provider who is able to solicit accurate patient feedback is then able to resolve patientspecific problems and provide appropriate reinforcement as necessary (arrows 9-10). This type of two-way communication and collaborative problem-solving leads to greater patient satisfaction and adherence (arrow 11) and enhanced treatment outcomes (arrow 12). The final arrow (14) illustrates the importance of past interactions and treatment experiences in establishing and maintaining a trusting relationship that is the cornerstone of effective health and pharmaceutical care.

Health collaboration model can play an important role in pharmacy practice and research:

i. It enables pharmacy practitioners and researchers to organize large amounts of information that would otherwise be confusing or difficult to interpret and use.

ii. It enables pharmacists to identify potential connections and implications that are not obvious when examining results from a single study or set of observations. iii. It can be used as a stimulus and guide for further discussion, evaluation, and practice development.

iv. It helps us see that the patient's behavior depends more upon the patient's beliefs, feelings, and interactions than on the patient's medical diagnosis or severity of illness.

v. It also helps us see pharmacists who have a good understanding of patient behavior can have a positive impact on treatment outcomes by providing quality instruction, support, monitoring, and collaborative problem-solving and reinforcement. ${ }^{103-106}$

\section{Conclusion}

The comparative study shows different perspective of patient behavior in modern world and in Bangladesh. Reasons are found to cultural and economic differences. Pharmacists and other healthcare providers also have different strategies to promote patient behavior change, spent times with patients. High patient activity change support system should validate their efficiency and professionalism. But reality is that no graduate pharmacist is working in retail pharmacies or Government hospitals of Bangladesh except very few tertiary private hospitals. To attain the ideal healthcare service doctor, pharmacist, nurse and other healthcare professionals must work together. It is noteworthy to mention that any interruption in the team work will disrupt the whole health system and patient care service will never be achieved. At the same time, physicians and pharmacists do not always ask patients about their medication concerns, beliefs, understandings, and behaviors. While these patient concerns can have detrimental effects on the patient's behavior, many patients are reluctant to complain or ask their providers about their medications. Providers who ask carefully designed, open-ended questions about patient concerns and adherence will be more likely to receive accurate patient feedback than those who wait for their patients to volunteer this information.

\section{Article summary}

Patients today are considered to be thinking, able decision makers who can play an important role in the treatment process. Because patients are now recognized as active individuals, more attention is being paid to ways of restoring health or slowing illness progression through improved provider-patient communication and patients' involvement in their own treatment. Emphasis therefore is placed on a range of patient treatment behaviors including sharing beliefs and expectations, asking questions, adhering to regimens, using home monitoring devices, keeping appointments, identifying and reporting side effects and drug-taking problems, and other valuable forms of communication that are necessary in contemporary health care.

\section{Acknowledgments}

It's a great honor and gratitude to be pharmacists in research and education process. All pharmacists, officials, journalists, magazine analysts and associates that I met in this purpose, were very kind and helpful. I'm thankful to Dr. Mamun Rashid, Assistant Professor of Pharmaceutics, Appalachian College of Pharmacy Oakwood, Virginia for his precious time to review my article and for his thoughtful suggestions. I'm also grateful to seminar library of Faculty of Pharmacy, University of Dhaka and BANSDOC Library, Bangladesh for providing me books, journal and newsletters. The greatest help was from students and colleagues who continually supported me in collection and data extraction from books, journals, newsletters and precious time in discussion followed by providing information on different types of cosmetics in use. A portion of this article is long 
been lectured as course material. So, it is very much helpful for me to deliver better than before as many more things are studied.

\section{Compliance with the ethical issues}

Ethics approval and consent to participate: Animal and Human experiment: N/A, Human Data Submission Approval: N/A

Consent for publication: Consent to publish Individual Person's data: N/A

Availability of data and materials: Data sharing: Data will be provided on request.

Funding: Funding from individual/Organization: No fund received from any individual/organization.

Authors' contributions: The individual contributions of authors: N/A.

\section{Conflicts of interest}

The author declares that he has no conflict of interest.

\section{References}

1. Manmohan T, Sreenivas G, Sastry VV, et al. Drug compliance and adherence to treatment. Journal of Evolution of Medical and Dental Sciences. 2012;1(3):142-159.

2. Fraser S. Concordance, compliance, preference or adherence. Patient Prefer Adherence. 2010;4:95-96.

3. Bell JS, Airaksinen MS, Lyles A, et al. Concordance is not synonymous with compliance or adherence. Br J Clin Pharmacol. 2007;64(5):710711 .

4. Poortaghi S, Raiesifar A, Bozorgzad P, et al. Evolutionary concept analysis of health seeking behavior in nursing: a systematic review. $B M C$ Health Serv Res. 2015;15:523.

5. Kim ES, Strecher VJ, Ryff CD. Purpose in life and use of preventive health care services. Proc Natl Acad Sci U S A. 2014;111(46):1633116336.

6. Adane M, Mengistie B, Mulat $\mathrm{W}$, et al. Utilization of health facilities and predictors of health-seeking behavior for under-five children with acute diarrhea in slums of Addis Ababa, Ethiopia: a community-based cross-sectional study. J Health Popul Nutr. 2017;36(1):9.

7. Krick JP, Sobal J. Relationships between health protective behaviors. $J$ Community Health. 1990;15(1):19-34.

8. Khoso PA, Yew VWC, Mutalib MHA. Comparing and Contrast Ing Health Behaviour with Illness Behaviour. Journal of Social Sciences and Humanities 2016;11(2):578-589.

9. Langlie JK. Interrelationships among preventive health behaviors: a test of competing hypotheses. Public Health Rep. 1979;94(3):216-225.

10. Harooni J, Hassanzadeh A, Mostafavi F. Influencing factors on health promoting behavior among the elderly living in the community. $J$ Educ Health Promot. 2014;3:40

11. Ping W, Cao W, Tan H, etal. Health protective behavior scale: Development and psychometric evaluation. PLoS One. 2018;8;13(1):e0190390.

12. Irwin MR. Why People Use Health Services. Milbank Q. 2005;83(4):10.

13. Sirri L, Grandi S. Illness behavior. Adv Psychosom Med. 2012;32:160181.

14. Lasselin J, Petrovic P, Olsson MJ, et al. Sickness behavior is not all about the immune response: Possible roles of expectations and prediction errors in the worry of being sick. Brain Behav Immun. 2018;74:213-221.
15. Stanislave VK, Sidney C. Health Behavior, Illness Behavior, and SickRole Behavior. Sick-Role Behavior Archives of Environmental Health: An International Journal. 1966;12(2):246-266.

16. Becker MH, Drachman RH, Kirscht JP. A new approach to explaining sick-role behavior in low-income populations. Am J Public Health. 1974;64(3):205-216.

17. Kasl SV, Cobb S. Health behavior, illness behavior, and sick-role behavior. II. Sick-role behavior. Arch Environ Health. 1966;12(4):531541 .

18. Kim HK, Lee M. Factors associated with health services utilization between the years 2010 and 2012 in Korea: using Andersen's Behavioral model. Osong Public Health Res Perspect. 2016;7(1):18-25.

19. Mueller C, Schur C, O'Connell J. Prescription drug spending: the impact of age and chronic disease status. Am J Public Health. 1997;87(10):16261629.

20. Payne J, Neutel I, Cho R, et al. Factors Associated with Women's Medication Use. BMC Womens Health. 2004;4(Suppl 1):S29.

21. Kessler RC. Epidemiology of women and depression. J Affect Disord. 2003;74(1):5-13.

22. Nierenberg AA, Trivedi MH, Fava M, et al. Family history of mood disorder and characteristics of major depressive disorder: A STAR (*) D (sequenced treatment alternatives to relieve depression) study. Journal of Psychiatric Research. 2007;41(3-4):214-221.

23. Pleck JH. The Forty-Nine Percent Majority: The Male Sex Role Psychology of Women Quarterly. 1977;2(1):79-80.

24. Verbrugge LM. Gender and health: an update on hypotheses and evidence. J Health Soc Behav. 1985;26(3):156-182.

25. Viera AJ, Thorpe JM, Garrett JM. Effects of sex, age, and visits on receipt of preventive healthcare services: a secondary analysis of national data. BMC Health Serv Res. 2006;6:15.

26. Grzywacz JG, Stoller EP, Brewer-Lowry AN, et al. Gender and health lifestyle: an in-depth exploration of self-care activities in later life. Health Educ Behav. 2012 Jun;39(3):332-340.

27. Hummer RA, Hernandez EM. The Effect of Educational Attainment on Adult Mortality in the United States. Popul Bull. 2013;68(1):1-16.

28. Kitko L, Hupcey JE. Factors that influence health-seeking behaviors of patients experiencing acute stroke. J Neurosci Nurs. 2008;40(6):333340 .

29. Gary BR. Ethnocultural Variations in the Experience of Pain. In: Thomas Hadjistavropoulos, Kenneth D Craig, editors. Pain Psychological perspectives. 2004. $391 \mathrm{p}$.

30. Pachter, LM. Cultural issues in pediatric care. In: Nelson's textbook of pediatrics. 1992.

31. Ortega AN, Rodriguez HP, Vargas Bustamante A. Policy dilemmas in Latino health care and implementation of the Affordable Care Act. Annu Rev Public Health. 2015;36:525-544.

32. Martz DM, Handley KB, Eisler RM. The relationship between feminine gender role stress, body image, and eating disorders. Psychology of Women Quarterly. 1995;19:493-508.

33. Siddiqui MA, Khan MF, Carline TE. Gender differences in living with diabetes mellitus. Mater Sociomed. 2013;25(2):140-142.

34. Nguyen H, Sorkin DH, Billimek J, et al. Complementary and alternative medicine (CAM) use among non-Hispanic white, Mexican American, and Vietnamese American patients with type 2 diabetes. $J$ Health Care Poor Underserved. 2014;25(4):1941-1955.

35. Turner J, Kelly B. Emotional dimensions of chronic disease. West J Med. 2000;172(2):124-128. 
36. Li H, Ji Y, Chen T. The roles of different sources of social support on emotional well-being among Chinese elderly. PLoS One. 2014;9(3):e90051.

37. Jimmy B, Jose J. Patient medication adherence: measures in daily practice. Oman Med J. 2011;26(3):155-159.

38. Kronish IM, Ye S. Adherence to cardiovascular medications: lessons learned and future directions. Prog Cardiovasc Dis. 2013;55(6):590-600

39. Bosworth HB, Granger BB, Mendys P, et al. Medication adherence: a call for action. Am Heart J. 2011;162(3):412-24.

40. Hattingh HL, Emmerton L, Ng Cheong Tin P, Green C. Utilization of community pharmacy space to enhance privacy: a qualitative study. Health Expect. 2016;19(5):1098-110.

41. Davis RE, Jacklin R, Sevdalis N, et al. Patient involvement in patient safety: what factors influence patient participation and engagement? Health Expectations. 2007;10(3):259-267.

42. Wancata LM, Hinshaw DB. Rethinking autonomy: decision making between patient and surgeon in advanced illnesses. Ann Transl Med. 2016;4(4):77.

43. Bradley JG, Zia MJ, Hamilton N. Patient preferences for control in medical decision making: a scenario-based approach. Fam Med. 1996;28(7):496-501.

44. Di Blasi Z, Harkness E, Ernst E, Georgiou A, Kleijnen J. Influence of context effects on health outcomes: a systematic review. Lancet. 2001;357(9258):757-762.

45. Ong LM, de Haes JC, Hoos AM, et al. Doctor-patient communication: a review of the literature. Soc Sci Med. 1995;40(7):903-918.

46. Institute of Medicine (US). Committee on Health and Behavior: Research, Practice, and Policy. Health and Behavior: The Interplay of Biological, Behavioral, and Societal Influences. USA: Washington (DC): National Academies Press (US); 2001.

47. Zeng-Treitler Q, Kim H, Hunter M. Improving patient comprehension and recall of discharge instructions by supplementing free texts with pictographs. AMIA Annu Symp Proc. 2008;6:849-853.

48. McCarthy DM, Waite KR, Curtis LM, et al. What did the doctor say? Health literacy and recall of medical instructions. Med Care. 2012;50(4):277-282.

49. Sudore RL, Schillinger D. Interventions to Improve Care for Patients with Limited Health Literacy. J Clin Outcomes Manag. 2009;16(1):20 29.

50. Badarudeen S, Sabharwal S. Assessing readability of patient education materials: current role in orthopaedics. Clin Orthop Relat Res. 2010;468(10):2572-2580.

51. Nielsen-Bohlman L, Panzer AM, Kindig DA. Health Literacy: A Prescription to End Confusion. Institute of Medicine (US) Committee on Health Literacy. 2004.

52. Metin S, Demirci H, Metin AT. Effect of health literacy of caregivers on survival rates of patients under palliative care. Scand J Caring Sci. 2019.

53. Spencer J, Hadden K, Brown H, et al. Considering Low Health Literacy: How Do the Pelvic Floor Distress Inventory-Short Form 20 and Pelvic Floor Impact Questionnaire-Short Form 7 Measure Up? Female Pelvic Med Reconstr Surg. 2019;25(2):145-148

54. Polite BN, Cipriano-Steffens TM, Liao C, et al. Investigation of a multimedia, computer-based approach to improve knowledge, attitudes, self-efficacy, and receptivity to cancer clinical trials among newly diagnosed patients with diverse health literacy skills. Cancer. 2019.

55. Reynolds R, Smoller S, Allen A, et al. Health Literacy and Health Outcomes in Persons Living with HIV Disease: A Systematic Review. AIDS Behav. 2019
56. Vernon J, Trujillo A, Rosenbaum S, et al. Low health literacy: implications for national health policy. University of Connecticut. Storrs, CT: National Bureau of Economic Research. 2007.

57. DeWalt DA, Broucksou KA, Hawk V, et al. Developing and testing the health literacy universal precautions toolkit. Nurs Outlook. 2011;59(2):85-94

58. Stewart DC, George J, Bond CM, et al. Views of pharmacist prescribers, doctors and patients on pharmacist prescribing implementation. Int $J$ Pharm Pract. 2009;17(2):89-94.

59. Akazawa M, Mikami A, Tamura Y, et al. Establishing a PharmacyBased Patient Registry System: A Pilot Study for Evaluating Pharmacist Intervention for Patients with Long-Term Medication Use. Pharmacy (Basel). 20186(1):12

60. Elizabeth JU. Development of Models to Predict Medication Noeadherence Based On a New Typology. Thesis and dissertations. 2009. 246-261.

61. Kelly DV, Young S, Phillips L, et al. Patient attitudes regarding the role of the pharmacist and interest in expanded pharmacist services. Can Pharm J (Ott). 2014;147(4):239-247.

62. Al-Arifi MN. Patients' perception, views and satisfaction with pharmacists' role as health care provider in community pharmacy setting at Riyadh, Saudi Arabia. Saudi Pharm J. 2012;20(4):323-330.

63. Anghel LA, Farcaş AM, Oprean RN. Medication adherence and persistence in patients with autoimmune rheumatic diseases: a narrative review. Patient Prefer Adherence. 2018;12:1151-1166.

64. Nepal G, Bhatta S. Self-medication with Antibiotics in WHO Southeast Asian Region: A Systematic Review. Cureus. 2018;10(4):e2428.

65. Ekor M. The growing use of herbal medicines: issues relating to adverse reactions and challenges in monitoring safety. Front Pharmacol. 2014;4:177.

66. Zullig LL, Blalock DV, Dougherty S, et al. The new landscape of medication adherence improvement: where population health science meets precision medicine. Patient Prefer Adherence. 2018;12:12251230.

67. Cutler RL, Fernandez-Llimos F, Frommer M, et al. Economic impact of medication non-adherence by disease groups: a systematic review. $B M J$ Open. 2018;8(1):e016982.

68. Naheed A, Haldane V, Jafar TH, et al. Patient pathways and perceptions of hypertension treatment, management, and control in rural Bangladesh: a qualitative study. Patient Prefer Adherence. 2018;12:1437-1449.

69. Jafar TH, Gandhi M, Jehan I, et al. Determinants of Uncontrolled Hypertension in Rural Communities in South Asia-Bangladesh, Pakistan, and Sri Lanka. Am J Hypertens. 2018;31(11):1205-1214.

70. Al Mansari A, Obeid Y, Islam N, et al. GOAL study: clinical and nonclinical predictive factors for achieving glycemic control in people with type 2 diabetes in real clinical practice. BMJ Open Diabetes Res Care. 2018;6(1):e000519.

71. Gate L, Warren-Gash C, Clarke A, et al. Promoting lifestyle behaviour change and well-being in hospital patients: a pilot study of an evidence-based psychological intervention. J Public Health (Oxf). 2016;38(3):e292-e300.

72. Shaikh RA, Siahpush M, Singh GK, et al. Socioeconomic Status, Smoking, Alcohol use, Physical Activity, and Dietary Behavior as Determinants of Obesity and Body Mass Index in the United States: Findings from the National Health Interview Survey. Int $J$ MCH AIDS. $2015 ; 4(1): 22-34$

73. Lasebikan VO, Ayinde O, Odunleye M, et al. Prevalence of alcohol consumption and alcohol use disorders among outdoor drinkers in public open places in Nigeria. BMC Public Health. 2018;18(1):400. 
74. Thakur JS, Paika R. Determinants of smokeless tobacco use in India Indian J Med Res. 2018;148(1):41-45.

75. Rai RK, Jaacks LM, Bromage S, et al. Prospective cohort study of overweight and obesity among rural Indian adults: sociodemographic predictors of prevalence, incidence and remission. BMJ Open. 2018;8(8):e021363.

76. $\mathrm{Hu} \mathrm{J}$, Amirehsani KA, Wallace DC, et al. The meaning of insulin to Hispanic immigrants with type 2 diabetes and their families. Diabetes Educ. 2012;38(2):263-270.

77. Clewley D, Rhon D, Flynn T, et al. Health seeking behavior as a predictor of healthcare utilization in a population of patients with spinal pain. PLoS One. 2018;13(8):e0201348.

78. Brownlee S, Chalkidou K, Doust J, et al. Evidence for overuse of medical services around the world. Lancet. 2017;390(10090):156-168.

79. Dixit SK, Sambasivan M. A review of the Australian healthcare system: A policy perspective. SAGE Open Med. 2018;6:2050312118769211.

80. Bukhari A, Pardhan A, Khan As. Superstitions regarding Health Problems in different EthnicGroups in Karachi. J Pak Med Assoc. 2002;52(8):383387.

81. Garg S, Anand T. Menstruation related myths in India: strategies for combating it. J Family Med Prim Care. 2015;4(2):184-186.

82. Vanderlee L, Ahmed S, Ferdous F, et al. Self-care practices and barriers to compliance among patients with diabetes in a community in rural Bangladesh. Int J Diabetes Dev Ctrie. 2016;36(3):320-326.

83. Sutradhar KB, Saha A, Huda $\mathrm{NH}$, et al. ddin R. Irrational U se of Antibiotics and Antibiotic Resistance in Southern Rural Bangladesh: Perspectives from Both the Physicians and Patients. Annual Research \& Review in Biology. 2014;4(9):1421-1430.

84. Paul R. Role of community pharmacists in patients' self-care and selfmedication. Integr Pharm Res Pract. 2015;4:57-65.

85. Jolly F, Suja A. Clinical pharmacists: Bridging the gap between patients and physicians. Saudi Pharm J. 2014;22(6):600-602.

86. Michie S, Richardson M, Johnston $\mathrm{M}$, et al. The behavior change technique taxonomy (v1) of 93 hierarchically clustered techniques: building an international consensus for the reporting of behavior change interventions. Ann Behav Med. 2013;46(1):81-95.

87. Carey RN, Connell LE, Johnston M, et al. Behavior Change Techniques and Their Mechanisms of Action: A Synthesis of Links Described in Published Intervention Literature. Ann Behav Med. 2018.

88. Torres-Robles A, Wiecek E, Cutler R, et al. Using Dispensing Data to Evaluate Adherence Implementation Rates in Community Pharmacy. Front Pharmacol. 2019;10:130.

89. Mohiuddin AK. Patient Compliance: An Untold Story or a Fairy Tale? Pharmaceut Reg Affairs. 2018;7:2.
90. .Christensen-Szalanski JJ, Northcraft GB. Patient compliance behavior: the effects of time on patients' values of treatment regimens. Soc Sci Med. 1985;21(3):263-273.

91. Ramsay MA. Conflict in the health care workplace. Proc (Bayl Univ Med Cent). 2001;14(2):138-139.

92. Van Keer RL, Deschepper R, Francke AL, et al. Conflicts between healthcare professionals and families of a multi-ethnic patient population during critical care: an ethnographic study. Crit Care. 2015;19:441.

93. Chellew S. Managing Disruptive Patient Behavior. 2016. 6 p.

94. Grissinger M. Disrespectful Behavior in Health Care: Its Impact, Why It Arises and Persists, And How to Address It-Part 2. PT. 2017;42(2):7477.

95. Chipidza F, Wallwork RS, Adams TN, et al. Evaluation and Treatment of the Angry Patient. Prim Care Companion CNS Disord. 2016;18(3).

96. Sansone RA, Sansone LA. Patient aggression: is the clinical practice setting safe? Innov Clin Neurosci. 2014;11(11-12):36-40.

97. Sammer CE, Lykens K, Singh KP, et al. What is patient safety culture? A review of the literature. J Nurs Scholarsh. 2010;42(2):156-165.

98. Youngberg B. Managing the Disruptive Patient: A Challenge to Patient and Provider Safety. 2012.

99. Steinman HK. A method for working with displeased patients-blast. $J$ Clin Aesthet Dermatol. 2013;6(3):25-28.

100. Mays GP, Halverson PK, Kaluzny AD. Collaboration to improve community health: trends and alternative models. Jt Comm J Qual Improv. 1998;24(10):518-540.

101. Committee on the Learning Health Care System in America; Institute of Medicine; Smith M, et al. Best Care at Lower Cost: The Path to Continuously Learning Health Care in America. Washington (DC): National Academies Press (US); A Continuously Learning Health Care System. 2013.

102. Pharmaceutical Press Website. The Health Collaboration Model: A Tool for Analyzing and Improving Patient Care.

103. Saulnier L. Are You Realizing the Full Potential of Pharmacy Practice in the Healthcare System? Can J Hosp Pharm. 2018;71(4):288.

104. Philip B, Weber RJ. Enhancing pharmacy practice models through pharmacists' privileging. Hosp Pharm. 2013;48(2):160-165.

105. Sanii Y, Torkamandi H, Gholami K, et al. Role of pharmacist counseling in pharmacotherapy quality improvement. $J$ Res Pharm Pract. 2016;5(2):132-137.

106. Web Medpro group. Risk Management Tools \& Resources. 